\title{
Study on Teaching Management System of Maritime Vocational Colleges based on Grey Theory
}

\author{
Ying LIAN \\ Tianjin Maritime College, Tianjin 300350, China
}

\begin{abstract}
With the rapid development of management science and technology, teaching management systems for maritime vocational colleges are urgently needed to be studied. In this research paper, based on customer satisfaction theory, a teaching management system evaluation index system for maritime vocational colleges is established from system performance, customer service and technical support. We adopt the general idea of fuzzy AHP methodology to determine the weight of indexes, grey evaluation method is used to evaluate teaching management system for maritime vocational college satisfaction comprehensively. In the final analysis, an example illustrates the application of the evaluation model of teaching management satisfaction system for maritime vocational colleges. The result indicates the effectiveness of our method.
\end{abstract} KEYWORD: Maritime Vocational Colleges; Teaching Management System; Grey Theory; AHP Method

\section{INTRODUCTION}

\subsection{Background Introduction}

Teaching management in maritime vocational colleges and universities is an extremely important part of the core and foundation of the institutions administration. The level of teaching management reflects the college (university) one of the aspects of management, which is related to the survival, development and university competitive position in the current society. A variety of academic information and reports, manual handling has been difficult to keep up with the modern management. With the development of computer and communication technology, the management of higher education in colleges and universities put forward higher request, "standardization, information network" is the inevitable choice of reform of teaching management. By improving the management information system, we can standardize management, to ensure that the teaching effect and improve the efficiency of management, and effectively improve the management of the academic standardization and modernization, lead to a virtuous circle of academic management. At present, many colleges and universities information construction has made remarkable achievements, but systematic, timeliness and the complexity of information processing, there are still many problems to be solved in the management of the information technology teaching. Such as, the planning and design is not entirely reasonable, the basic accuracy of the information and the overall quality of academic administrators need to be further improved, the hardware used in teaching management facilities needs to be replaced, and so on.

\subsection{Literature Review}

There are lots of research results which have been well studied and researched. Zhao Jianping etc. built a teaching management system by distributed method [1]; Feng Siyuan built teaching management system based on database [2], Peng Taile built the teaching management system through the campus network [3], etc. Research on evaluation of teaching management system is few. Although there are many on the evaluation of software systems [4], the Teaching management has its own particularity, how to establish scientific and reasonable evaluation system for university teaching management system has become a university problem to be solved. Therefore, we need scientific and effective indexes to evaluate the teaching management system to help us understand the problems and deficiencies in academic system, which could help to improve the user satisfaction of the academic system. 


\section{TEACHING MANAGEMENT SYSTEM FOR MARITIME VOCATIONAL COLLEGES}

\subsection{Charts Analysis}

The figure 1 shows the general steps. In reference to a number of customer satisfaction evaluation system and the management systems based on the evaluation index system, the text establishes the teaching management system evaluation index system from the system performance, user service and technical levels, in which level of system performance contains seven sub factors, user service level includes four sub factors, technical support level includes four sub factor indicators.

\begin{tabular}{|c|c|c|}
\hline \multirow{18}{*}{$\begin{array}{c}\mathbf{T} \\
\mathbf{M} \\
\mathbf{S} \\
\mathbf{S} \\
\mathbf{I} \\
\mathbf{S}\end{array}$} & $\begin{array}{l}\text { First-Level } \\
\text { Indicators }\end{array}$ & Second-level indicators \\
\hline & \multirow{7}{*}{$\begin{array}{c}\text { System } \\
\text { performance }\end{array}$} & Functional completeness \\
\hline & & Functional utility \\
\hline & & Information timeliness \\
\hline & & Reliability of information \\
\hline & & Responsiveness \\
\hline & & The degree of personalization \\
\hline & & System stability \\
\hline & \multirow{4}{*}{$\begin{array}{c}\text { User } \\
\text { service }\end{array}$} & Degree of user-friendly \\
\hline & & Has the help information \\
\hline & & Retrieval convenience \\
\hline & & Relevance of search results \\
\hline & \multirow{6}{*}{$\begin{array}{c}\text { Technical } \\
\text { support }\end{array}$} & Information Classification \\
\hline & & reasonable \\
\hline & & System hierarchical structure \\
\hline & & The speed of data inducting \\
\hline & & and deriving \\
\hline & & System renewal frequency \\
\hline
\end{tabular}

Figure 1. Evaluation Index Analysis (TMSSIS)

\subsection{Theoretical Discuss}

Teaching management system satisfaction index system (TMSSIS) is the design, construction, and an important basis for improving the academic system, it can also be used in comparison between the qualitative judgments of different teaching management system. The selection of teaching system performance index system will have a huge impact on evaluation results. Meanwhile, whether the target setting is scientific will also affect the ability to effectively carry out evaluation of the work itself. Therefore, to design a scientific, reasonable and feasible indicator evaluation system is particularly important. The fundamental purpose of academic system is to improve the efficiency and accuracy of academic work [5], and its goals lies in the user system, the use of the Senate that the Senate system, user satisfaction for the Senate, whether the system is to achieve its original goal of playing a decisive role. Therefore, this article establishes the teaching management system evaluation index system based on customer satisfaction.

\section{GREY EVALUATION METHODOLOGY}

\subsection{The initiation of index set}

User satisfaction with academic system is mostly a psychological index, a user using the administration system in the process of actual experience compared to its expected level, must to turn it into the actual number to quantitative analysis. Due to the grey characters of human cognition and feeling, grey evaluation method is used. The establishment of a multi-level structure of customer satisfaction evaluation index system. Evaluation of the mathematical expression for the combined $C=\left(C_{1}, C_{2}, C_{3}, \cdots, C_{n}\right), C_{i}(i=1,2,3, \cdots, n)$ are guidelines for the evaluation index system of the first i-layer indicators. First i set up under the broad categories of indicators also set up an evaluation index, then $C_{i}\left(F_{i 1}, F_{i 2}, F_{i 3}, \ldots F_{i n}\right), F_{i j}$ as the standard ilayer of the first indicators of factors, indicators under the $\mathrm{j}$-factor, the indicators under each criterion layer and so on.

\subsection{The calculation of index weight set}

As different evaluation indicators have different influence to the overall evaluation goal G, fuzzy analytic hierarchy process method is used to calculate the weight of each index. Fuzzy Analytic Hierarchy Process (FAHP) uses fuzzy matrix instead of comparison matrix in AHP for judgment, it solves the conflict between scopes with degree of consistency in AHP, with more scientific consistency in inspection standards [6]. For the multi-level comprehensive evaluation index, FAHP makes expert easier to judge and more convenient compared with AHP. Compare sub-indexes with the same factor standard, determine relative importance of indexes by using 1-9 scale method proposed by Saaty, which construct the judging matrix $A\left(a_{i j}\right)$ of each layer. Calculate the eigenvectors corresponding to the largest eigenvalue $\lambda_{\max }$ in judging matrix, which is the order of importance for indexes and the weight distributable after normalized. Finally, make the consistency testing which formula is $C R=\frac{C I}{R I}$ where $C I=\frac{\lambda_{\max }-n}{n-1}$. In the formula, RI is the average random consistency index of judging matrix given from a large number of tests. Usually judging matrixes tally with the consistency condition when $\mathrm{CR}<0.1$, the weight distribution is reasonable, the values of eigenvector corresponding judging matrix are the weights for indexes to their upper factor; Otherwise, indexes must be modified using 
correction method provided by Saaty. Set the weight vector for $\mathrm{n}$ factors are the following $\bar{w}=\left(w_{1}, w_{2}, w_{3}, \ldots w_{n}\right)$, the weight of each index $F_{i j}$ vector under the i-th factor $C_{i}$ is the following $w_{i}=\left(w_{i 1}, w_{i 2}, w_{i 3}, \ldots w_{i n}\right)$.

\subsection{The assessment criteria set}

As the qualitative indicators, describe the pros and cons with different rating methods; the quantitative indicators, their advantages and disadvantages level data can be divided into a range of levels. If take the grade with 5 levels, such as "very good, good, general, bad, very bad", then the number of level of evaluation $\mathrm{h}=5$. Different levels (grey type) e of the scoring criteria used to measure with $S_{e}$, such as "9, 7, 5, 3, 1", the score between the adjacent levels could obtained the average and so on.

\subsection{The vector and assessment grey function}

Organizing users to score these indexes according to the standard rating scale and fill in the grading table. Set the number of users is $\mathrm{K}$, the score to index $F_{i j}$ with the t-th user is $S_{i j}^{(t)}$, therefore, all scoring users' scores to the index of $F_{i j}$ composite a vector of evaluation value $\bar{S}_{i j}, \bar{S}_{i j}=\left(s_{i j}^{(1)}, s_{i j}^{(2)}, s_{i j}^{(3)}, \ldots s_{i j}^{(k)},\right)$. Then we Set grey rating as e, $\mathrm{e}=1,2, \ldots, \mathrm{h}$, the grey date and definite weighted function described as follows: (1) Very good, the definition is shown in formula 1 ; (2)Medium, the definition is shown in formula 2; (3) Very poor, the definition is shown in formula 3.

$$
\begin{aligned}
& f_{1}\left(s_{i j}^{(t)}\right)=\left\{\begin{array}{l}
S_{i j}^{(t)} / S_{1}, s_{i j}^{(t)} \in\left[0, S_{1}\right) \\
1, s_{i j}^{(t)} \in\left[S_{1}, \infty\right) \\
0, s_{i j}^{(t)} \in[0, \infty)
\end{array}\right. \\
& f_{e}\left(s_{i j}^{(t)}\right)=\left\{\begin{array}{l}
S_{i j}^{(t)} / S_{e}, s_{i j}^{(t)} \in\left[0, S_{e}\right) \\
2 S_{e}-S_{i j}^{(t)} / S_{e}, s_{i j}^{(t)} \in\left[S_{e}, 2 S_{e}\right) \\
0, s_{i j}^{(t)} \in\left[0,2 S_{e}\right)
\end{array}\right. \\
& f_{h}\left(s_{i j}^{(t)}\right)=\left\{\begin{array}{l}
1, s_{i j}^{(t)} \in\left[0, S_{h}\right) \\
\left(2 S_{h}-S_{i j}^{(t)}\right) / S_{h}, s_{i j}^{(t)} \in\left[S_{h}, 2 S_{h}\right) \\
0, s_{i j}^{(t)} \in\left[0,2 S_{h}\right)
\end{array}\right.
\end{aligned}
$$

\subsection{The grey clustering and result}

Set the comprehensive evaluation result of $C_{i}$ as $\varsigma_{i}$, then $\varsigma_{i}=w_{i} \times R_{i}=\left\{\varsigma_{i 1}, \varsigma_{i 2}, \ldots, \varsigma_{i h}\right\}$. Integrate these comprehensive evaluation results $\varsigma_{i}$, the grey evaluation weighted matrix $\varsigma_{C}=\left\{\varsigma_{1}, \varsigma_{2}, \ldots, \varsigma_{n}\right\}$. According to the comprehensive evaluation results $\varsigma_{i}$ and $\mathrm{G}$, determine their respective grey type according to the principle of maximum proximity.

\section{EXPERIMENTAL ANALYSIS}

In this section, a college teaching management system satisfaction evaluation as an example to be illustrated the application of this paper's evaluation model. The steps are as follows. Step1, determine customer satisfaction evaluation indexes. According to above analysis, the teaching management system satisfaction evaluation indexes system is shown in figure 1 , which is divided into three-level indicators and 15 indexes.

Step 2, determine the weight of indexes. FAHP is used to determine weight of indexes, adopt the square-root matrix method to calculate the maximum characteristic root and characteristic vector. The weight vector of three indicators is $w=(0.368,0.333,0.299)$. Among them, the weight vector of second-level indicators of system performance layer is $w_{1}=(0.103,0.172,0.172,0.241$, $0.103,0.034,0.172$ ), the weight vector of secondlevel indicators of User service layer is $w_{2}=(0.314$, $0.151,0.367,0.178)$, the weight vector of secondlevel indicators of Technical support layer is $w_{3}=(0.153,0.107,0.360,0.380)$, All judging matrixes passed the consistency test.

Step 3, select eight individuals from the Tianjin Maritime College as evaluation users. Organize these users to score these indexes according to the standard rating scale and fill in the grading table. Take the number of level of evaluation $h=5$, which named "very good, good, general, bad, very bad", and different levels (grey type) e of the scoring criteria used to measure with "9, 7, 5, 3, 1", the score between the adjacent levels could obtained the average.

Step 4, carry out grey cluster analysis. According to the definite weight corresponding to all grey type evaluation value matrix, the grey evaluation weight vector of three types of indicators are obtained. According to index weight coefficient, calculate the comprehensive evaluation results of three types of indicators and overall evaluation. The comprehensive evaluation results of teaching management system in Tianjin Maritime College as follows:

The evaluation result of system performance type as follows: $1=\{0.12,0.36,0.27,0.18,0.07\}$, The definite value of the second grey category is up to 0.36 , which is the max. According with the principle of maximum proximity, it belongs to "good" level; 
The evaluation result of user service type as follows: $2=\{0.09,0.16,0.37,0.27,0.11\}$, The definite value of the third grey category is up to 0.37 , which is the max. According with the principle of maximum proximity, it belongs to "general" level; The evaluation result of technical support type as follows: $3=\{0.07,0.22,0.35,0.30,0.06\}$, The definite value of the third grey category is up to 0.37 , which is the max. According with the principle of maximum proximity, it belongs to "general" level; Overall satisfaction with the system evaluation results as follows: $\mathrm{G}=\{0.10,0.24,0.33,0.25,0.08\}$. The definite value of the third grey category is up to 0.37 , which is the max. According with the principle of maximum proximity, it belongs to "general" level. The results shows that the School's teaching management system comprehensive satisfaction level is "general" level, in which system performance is at a "good" level, customer service and technical support levels are located in the general level. In order to improve this school's teaching management system, user service and technical support levels should to be made improvements.

\section{SUMMARY AND CONCLUSION}

In this research paper, based on customer satisfaction theory, a teaching management system evaluation index system for maritime vocational colleges is established from system performance, customer service and technical support. We adopt the general idea of fuzzy AHP methodology to determine the weight of indexes, grey evaluation method is used to evaluate teaching management system for maritime vocational college satisfaction comprehensively. Teaching management systematic evaluation is the basis of continuous improvement. Based on the theory of satisfaction, this paper establishes the teaching management system evaluation indexed system, and uses the grey evaluation method to calculate out the evaluation system of comprehensive evaluation value. By the evaluation index system and grey evaluation method, teaching management system could have a more comprehensive and objective understanding, and provide an effective reference to improve the management level. In the future, to enhance the accuracy of the model, we plan to use some mathematical analysis [7-11] and system level analysis [12-14] to improve the proposed system.

\section{REFERENCES}

[1] Saaty, Thomas L. "Analytic hierarchy process." Encyclopedia of Operations Research and Management Science. Springer US, 2013. 52-64.

[2] Ergu, Daji, et al. "The analytic hierarchy process: task scheduling and resource allocation in cloud computing environment." The Journal of Supercomputing 64. 3 (2013): 835-848.

[3] Christos Douligeris \& Ian J. Pereira, "A Telecommunications Quality Study Using the Analytic Hierarchy Process," IEEE Journal on Selected Areas in Communications, Vol. 12, No. 2, 1994.

[4] F. Zahedi, "The analytic Hierarchy process-A survey of the method and its applications," Interfaces, Vol. 16, pp. 343-350, 1977.

[5] V.S. Lai, R. P. Trueblood \& B. K. Wong "Software selection: a case study of the application of the analytical hierarchical process to the selection of a multimedia authoring system," Information \& Management, Vol. 25, No. 2, 1992.

[6] Maggie, C. Y. Tam, \& V. M. Rao Tummala, "An application of the AHP in vendor selection of a telecommunications system," Omega, Vol. 29, pp. 171182,2001

[7] Deb, Kalyanmoy. "Multi-objective optimization." Search methodologies. Springer US, 2014. 403-449.

[8] Drummond, LM Grana, F. M. P. Raupp, and B. F. Svaiter. "A quadratically convergent Newton method for vector optimization." Optimization 63.5 (2014): 661-677.

[9] Xu, Biao, et al. "On reverse Hilbert-type inequalities." Journal of Inequalities and Applications 2014.1 (2014): 198.

[10] Yang, Bicheng, and Qiang Chen. "A more accurate halfdiscrete reverse Hilbert-type inequality with a nonhomogeneous kernel." Journal of Inequalities and Applications 2014.1 (2014): 1-13.

[11] Yang, Bicheng. "A Multidimensional Discrete HilbertType Inequality." International Journal of Nonlinear Analysis and Applications 5.1.

[12] Holden, Richard J., Christiane C. Schubert, and Robin S. Mickelson. "The patient work system: An analysis of selfcare performance barriers among elderly heart failure patients and their informal caregivers." Applied ergonomics 47 (2015): 133-150.

[13] Liu, Baoding. "Uncertain Reliability Analysis." Uncertainty Theory. Springer Berlin Heidelberg,

[14] Rezzouk, H., and A. Mellit. "Feasibility study and sensitivity analysis of a stand-alone photovoltaic-dieselbattery hybrid energy system in the north of Algeria." Renewable and Sustainable Energy Reviews 43 (2015): 1134-1150. 